\title{
Volatilização de amônia com aplicação de uréia na superfície do solo, no sistema plantio direto ${ }^{1}$
}

\author{
Ammonia volatilization after urea surface applied in corn no-tillage
}

\author{
Clovis Orlando Da Ros ${ }^{2}$ Celso Aita ${ }^{3}$ \\ Sandro José Giacomini ${ }^{4}$
}

\section{RESUMO}

Com o objetivo de avaliar o efeito dos resíduos culturais de aveia preta (Avena strigosa), dispostos na superfície do solo, nas perdas de $N$ por volatilização de amônia, conduziuse um experimento a campo, em 2002/03, na UFSM (RS), em um Argissolo Vermelho distrófico arênico. $O$ delineamento experimental foi o inteiramente casualizado, com três repetições. Os tratamentos constituíram da aplicação de uréia no milho, na presença e na ausência de resíduos culturais de aveia, em três épocas (pré-semeadura, semeadura e em cobertura). A uréia foi aplicada a lanço, sem incorporação ao solo, na dose equivalente a $50 \mathrm{~kg} \mathrm{ha} \mathrm{ha}^{-1}$ de $\mathrm{N}$, em cada época. Os resíduos culturais diminuíram os fluxos de volatilização de amônia quando eles proporcionaram maior umidade do solo no momento da aplicação da uréia, em relação ao solo descoberto. Em condições semelhantes de umidade de solo, entre os tratamentos com e sem resíduos culturais, houve maior volatilização de amônia, quando a uréia foi aplicada sobre os resíduos culturais. Quando ocorreu chuva no dia posterior a aplicação da uréia, não houve efeito dos resíduos culturais na volatilização de amônia. Na soma das três épocas de aplicação de uréia na cultura do milho, a quantidade de amônia volatilizada não diferiu entre os tratamentos com e sem resíduos culturais, com média de $17 \%$ de perda do $N$-uréia aplicado.

Palavras-chave: dinâmica do $N$, resíduos culturais, milho, perda de $N$

\section{ABSTRACT}

The experiment was carried out in 2002/03, at the Federal University of Santa Maria, State of Rio Grande do Sul,
Brasil, in a typic Haoludal under six years of no-tillage to evaluate the effects of black oat residues left at soil surface on ammonia volatilization. The experiment was in a completely randomized design with three replications. The treatments were urea applied with and without surface residue in three times: before seeding; seeding and; topdressing. The urea was spread at a rate of $50 \mathrm{~kg}$ $h a^{-1}$ of $N$ each time. The residues reduced the ammonia fluxes, as compared to bare soil, when under residues had higher soil moisture at urea application. On the other hand, when soil moisture for crop residue treatments were similar to bare soil the former had higher ammonia volatilization. When there was rainfall right after urea application, the treatments showed same volatilization flux. Considering the three timing of urea application for corn, the amount of volatilized ammonia was similar to conditions of with and without crop residues adding up $17 \%$ of $\mathrm{N}$-urea applied.

Key words: $N$ dynamics, crop residues, corn, loss of $N$.

\section{INTRODUÇÃO}

As perdas de nitrogênio (N) por volatilização ocorrem na hidrólise enzimática da uréia no solo, com a produção de amônia $\left(\mathrm{NH}_{3}\right)$. A diminuição do potencial de perdas ocorre quando esse gás passa para o íon amônio $\left(\mathrm{NH}_{4}{ }^{+}\right)$, que depende do $\mathrm{pH}$ em torno do grânulo da uréia e da umidade do solo. Essa passagem é intensificada pela difusão da amônia no solo e depende da textura, porosidade,

\footnotetext{
${ }^{1}$ Parte da Tese de Doutorado apresentada pelo primeiro autor ao Programa de Pós-graduação em Ciência do Solo, Universidade Federal de Santa Maria (UFSM), Santa Maria, RS, Brasil

${ }^{2}$ Departamento de Ciências Agrárias, Curso de Agronomia, Universidade de Cruz Alta (UNICRUZ). CP 858, 98025-810, Cruz Alta, RS, Brasil. E-mail: daros@unicruz.edu.br. Autor para correspondência.

${ }^{3}$ Departamento de Solos, UFSM, Santa Maria, RS, Brasil.

${ }^{4}$ Programa de Pós-graduação em Ciência do Solo, UFSM, Santa Maria, RS, Brasil.
} 
umidade e da capacidade do solo em reter o amônio (RODRIGUES \& KIEHL, 1986; SENGIK \& KIEHL, 1995a; LARA CABEZAS et al., 1997a; COSTA et al., 2003).

A incorporação da uréia ao solo é uma alternativa para reter maior quantidade de amônio no solo e para minimizar as perdas de amônia por volatilização (LARA CABEZAS et al., 2000 e SANGOI et al., 2003). No sistema plantio direto, portanto, essa prática não está acontecendo, pois além da uréia ser aplicada a lanço e sem incorporação ao solo, é realizada sobre os resíduos culturais. As perdas de $\mathrm{N}$ nesse sistema pode chegar a $78 \%$ do $\mathrm{N}$ aplicado (LARA CABEZAS et al., 1997b)

A magnitude das perdas de amônia por volatilização em função da presença dos resíduos culturais é difícil de prever. Se, por um lado, eles podem aumentar a concentração e a atividade da urease, o que aumentaria a volatilização de amônia (NELSON et al., 1980; ECKERT et al., 1986; McINNES et al., 1986; MELLO, 1987; MOAL et al., 1995), por outro lado, os resíduos culturais, na superfície do solo diminuem a temperatura e a perda de umidade por evaporação (BRAGAGNOLO \& MIELNICZUK, 1990), além de aumentar a CTC do solo (FALLEIRO et al., 2003; SOUZA \& ALVES, 2003), o que poderia diminuir a volatilização de amônia (CERETTA, 1997).

Este trabalho teve por objetivo quantificar as perdas de $\mathrm{N}$ por volatilização de amônia, com a aplicação de uréia na superfície e sem incorporação ao solo, em diferentes épocas no milho, na presença e na ausência de resíduos culturais de aveia preta.

\section{MATERIAL E MÉTODOS}

O experimento foi conduzido a campo, durante o ano agrícola 2002/2003, na área experimental do Departamento de Solos, da Universidade Federal de Santa Maria (RS), localizada a $29^{\circ} 45^{\prime}$ Latitude Sul , Longitude $53^{\circ} 42^{\prime} \mathrm{W}$ GrW e altitude de $95 \mathrm{~m}$. O clima dessa região, segundo a classificação de Koeppen, é subtropical úmido, tipo Cfa2. O solo é classificado como um Argissolo Vermelho distrófico arênico (EMBRAPA, 1999), com textura superficial franco arenosa, pertencente à Unidade de Mapeamento São Pedro (BRASIL, 1973).

O delineamento experimental foi o inteiramente casualizado, com três repetições. Os tratamentos constituíram da combinação de três épocas de aplicação de uréia no milho, na presença e na ausência de resíduos culturais de aveia, além de um tratamento sem aplicação de uréia. As épocas de aplicação de uréia no milho foram na pré-semeadura, semeadura e em cobertura. A quantidade de $\mathrm{N}$, na forma de uréia, foi de $50 \mathrm{~kg} \mathrm{ha}^{-1}$, em cada época, aplicada a lanço, sem incorporação ao solo. As aplicações de uréia, em todas as épocas, foram realizadas no final da tarde, entre $16 \mathrm{e} 19 \mathrm{~h}$, e a primeira avaliação de volatilização de amônia foi feita no início da manhã do dia seguinte ( \pm 9 h). Imediatamente antes da aplicação da uréia, foi determinada a umidade gravimétrica do solo, na camada de zero a $10 \mathrm{~cm}$.

As perdas de $\mathrm{N}$ por volatilização de amônia $\left(\mathrm{N}-\mathrm{NH}_{3}\right)$ foram quantificadas por meio de um sistema semi-aberto estático, proposto por NÖMMIK (1973), com algumas adaptações (Figura 1). As câmaras coletoras, construídas a partir de cilindros de cloro polivinil (PVC) com $200 \mathrm{~mm}$ de diâmetro e $400 \mathrm{~mm}$ de altura, foram encaixadas sobre bases, também de PVC com $70 \mathrm{~mm}$ de altura, as quais foram introduzidas no solo até uma profundidade de $30 \mathrm{~mm}$. Sobre os cilindros, foram encaixados suportes de metal, aos quais foi acoplada uma tampa protetora ( $300 \mathrm{~mm}$ de diâmetro), para impedir que a precipitação pluviométrica e os raios solares atingissem o interior do cilindro.

As câmaras coletoras foram instaladas entre as linhas de semeadura do milho, imediatamente antes das aplicações da uréia. Em cada câmara coletora, foram colocadas duas esponjas de $20 \mathrm{~mm}$ de espessura e 28 de densidade. Elas foram embebidas com uma solução contendo ácido fosfórico $\left(50 \mathrm{ml} \mathrm{L}^{-1}\right)$ e glicerina $\left(40 \mathrm{ml} \mathrm{L}^{-1}\right)$. A primeira esponja foi colocada na parte inferior da câmara, a uma altura de $15 \mathrm{~cm}$ do solo, com o objetivo de captar somente a amônia que foi volatilizada na parte interna das câmaras. A segunda foi colocada na parte superior da câmara, a $30 \mathrm{~cm}$ do solo, para captar a amônia externa às câmaras, evitando a contaminação da esponja inferior.

Foram efetuadas seis trocas das esponjas nas primeiras 70,0 horas após a aplicação da uréia na pré-semeadura e nas primeiras 89,5 horas após a aplicação da semeadura. Na aplicação da uréia em cobertura, as esponjas foram trocadas sete vezes, no período de 118,75 horas. As primeiras cinco trocas das espojas foram realizadas em intervalos aproximados de 12 horas. Quando houve duas trocas diárias, a primeira foi realizada na primeira hora da manhã e a segunda no final da tarde. Após cada coleta, foi colocada, no interior das câmaras, uma quantidade de água equivalente à chuva ocorrida no período. $\mathrm{Na}$ figura 2, estão indicadas a distribuição das precipitações pluviométricas e as temperaturas do ar.

A amônia retida nas esponjas, na forma de fosfato de amônio, foi extraída mediante oito a 10 lavagens sucessivas com uma solução de $\mathrm{KCl}(1 \mathrm{~mol}$ $\mathrm{L}^{-1}$ ). Após o ajuste do volume desta solução para

Ciência Rural, v.35, n.4, jul-ago, 2005. 


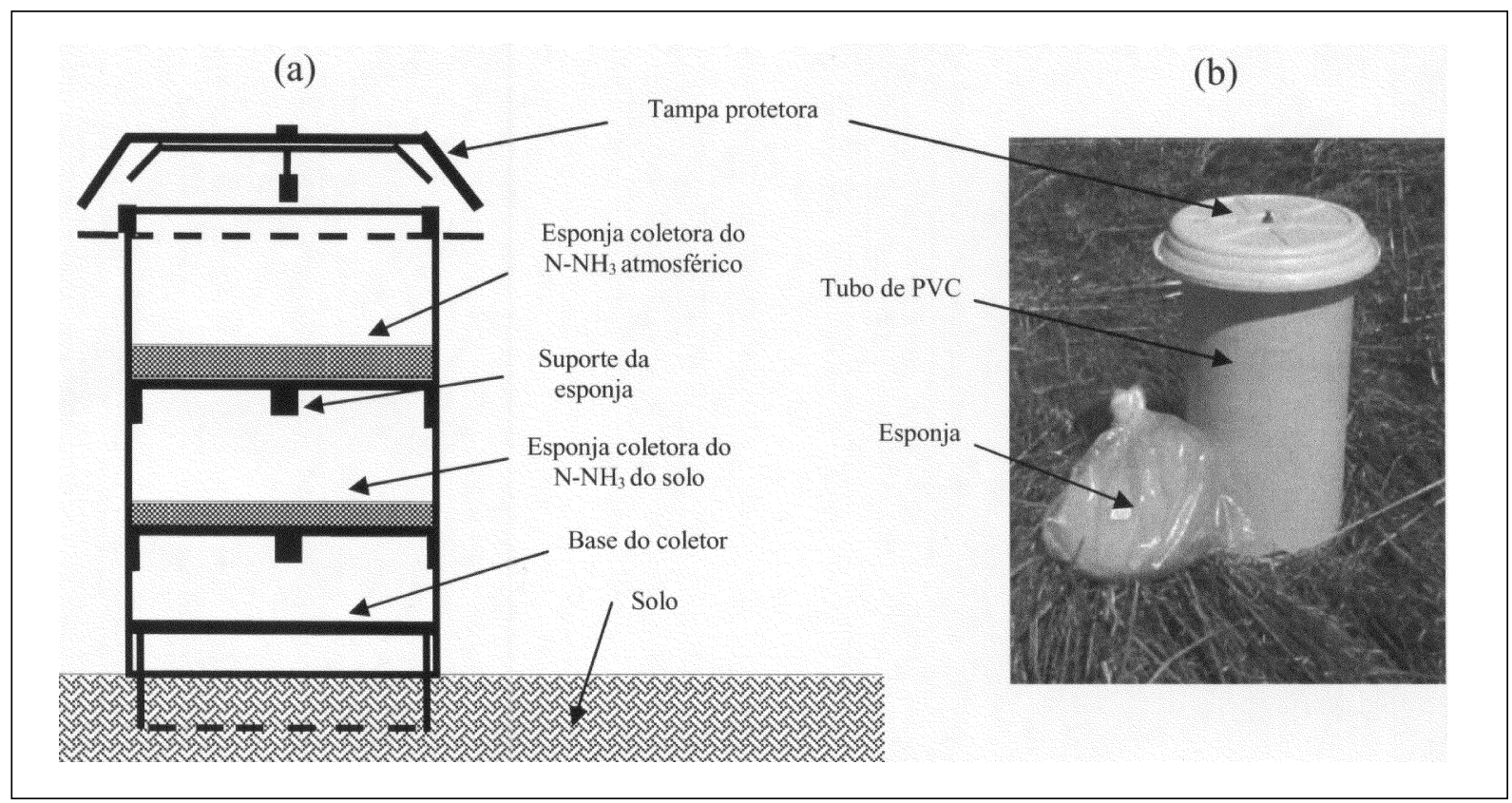

Figura 1 - Esquema (a) e foto (b) do dispositivo utilizado para medir a volatilização de amônia.

500ml, procedeu-se à destilação de uma alíquota de $20 \mathrm{ml}$ em destilador de arraste de vapores, adicionandose $0,2 \mathrm{~g}$ de $\mathrm{MgO}$ em cada amostra e posterior titulação com $\mathrm{H}_{2} \mathrm{SO}_{4}$ (TEDESCO et al., 1995).
Os dados foram submetidos à análise da variância e as médias de tratamentos comparadas pelo teste de Tukey, a 5\% de probabilidade de erro.

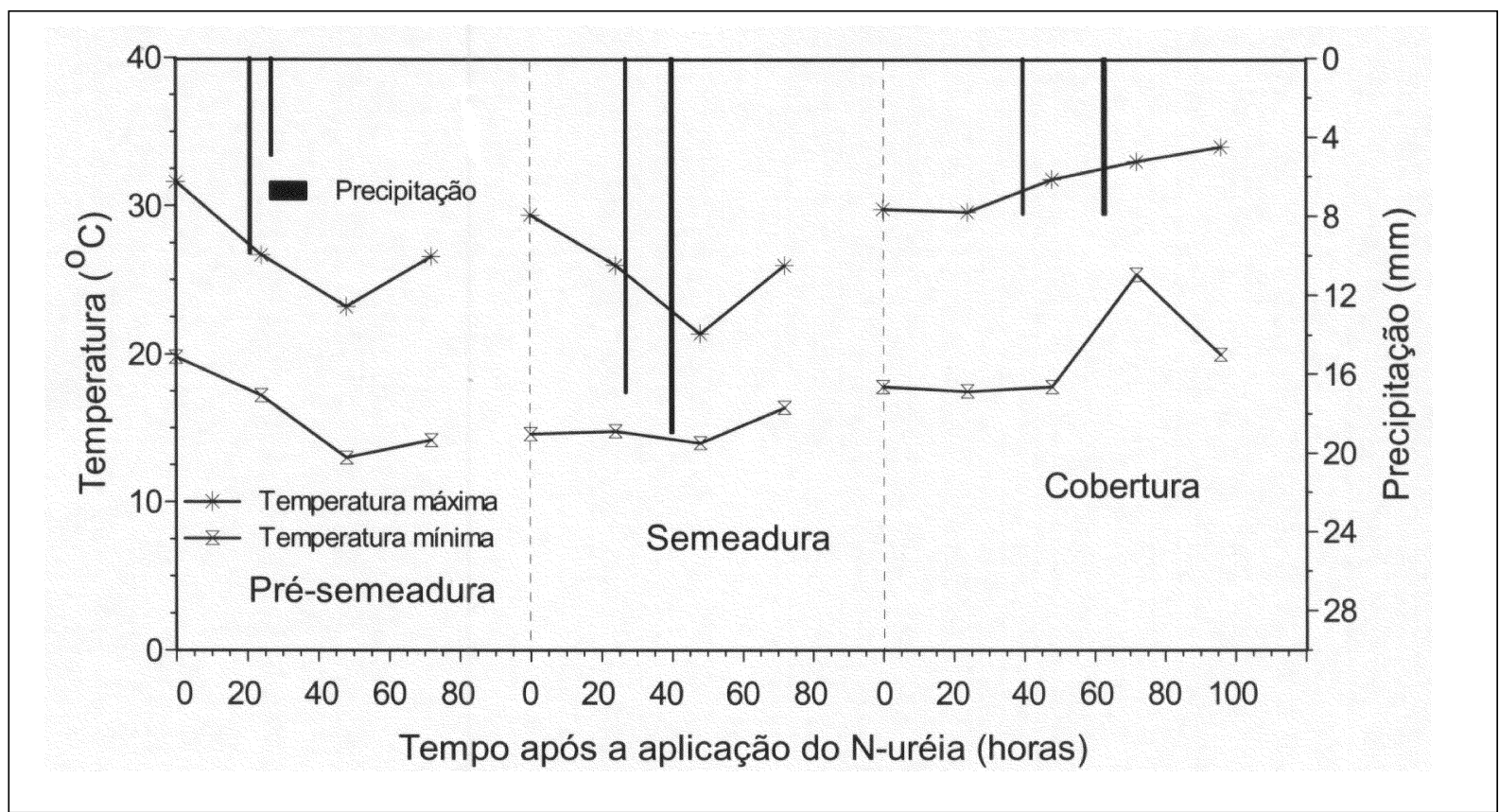

Figura 2 - Temperaturas do ar e precipitações pluviométricas, no período de avaliação da volatilização de amônia, após a aplicação da uréia na pré-semeadura, semeadura e em cobertura no milho.

Ciência Rural, v.35, n.4, jul-ago, 2005. 


\section{RESULTADOSE DISCUSSÃO}

Os fluxos de volatilização de amônia foram baixos nos tratamentos sem uréia. Nos tratamentos com uréia, os maiores fluxos de volatilização de amônia foram observados na segunda avaliação, realizada aproximadamente 20 horas após a aplicação da uréia (Figura 3). Essa cinética foi observada em outros estudos, tendo sido verificado que o processo inicia logo após a aplicação da uréia pela rápida hidrólise no solo (RODRIGES \& KIEHL, 1986; SENGIK \& KIEHL, 1995a; LARA CABEZAS et al., 1997a; COSTA et al., 2003). Normalmente, a máxima perda de amônia por volatilização concentra-se nos primeiros seis dias após a aplicação do fertilizante (AL-KANANI et al., 1991; SENGIK \& KIEHL, 1995a e 1995b; SANGOI et al., 2003b).

A análise da variância apresentou interação significativa entre as épocas de aplicação de uréia e a presença ou ausência de resíduos culturais de aveia na superfície do solo (Figuras 3 e 4). Na aplicação da uréia na pré-semeadura do milho, não houve diferença significativa entre os tratamentos com e sem resíduos culturais, tanto nos fluxos de volatilização (Figura 3) como na volatilização acumulada de amônia (Figura 4). $\mathrm{O}$ alto teor de umidade do solo no momento da aplicação da uréia na pré-semeadura (Tabela 1) e, principalmente, a precipitação pluviométrica que ocorreu na manhã do dia posterior à aplicação (Figura 2) devem ter anulado o efeito dos resíduos culturais na perda de $\mathrm{N}$ por volatilização.

O umedecimento do solo, imediatamente após a aplicação da uréia, é mais importante do que a condição de umidade do solo no momento da aplicação (LARA CABEZAS et al., 1997b), principalmente quando a uréia é aplicada na superfície e sem incorporação ao solo. A água diminui a volatilização da amônia se for suficiente para diluir a concentração de oxidrilas $\left(\mathrm{OH}^{-}\right)$, ao redor dos grânulos de uréia, que foram produzidos na reação de hidrólise, além de proporcionar a incorporação da uréia no solo (LARA CABEZAS et al., 1997a).

$\mathrm{Na}$ semeadura, houve precipitação pluviométrica somente no início da tarde do dia posterior à aplicação da uréia (Figura 2). Assim, os fluxos de volatilização de amônia, que ocorreram antes da precipitação, foram maiores na presença dos resíduos culturais (Figura 3 ) e contribuíram para a maior quantidade acumulada de amônia volatilizada (Figura 4). O menor contato da uréia com o solo (CERETTA, 1997) e a maior atividade da urease na presença dos resíduos culturais, em relação à ausência dos mesmos (NELSON et al., 1980; ECKERT etal., 1986; McINNES etal., 1986; MELLO, 1987; MOAL al.,1995), devem ter sido os fatores que mais

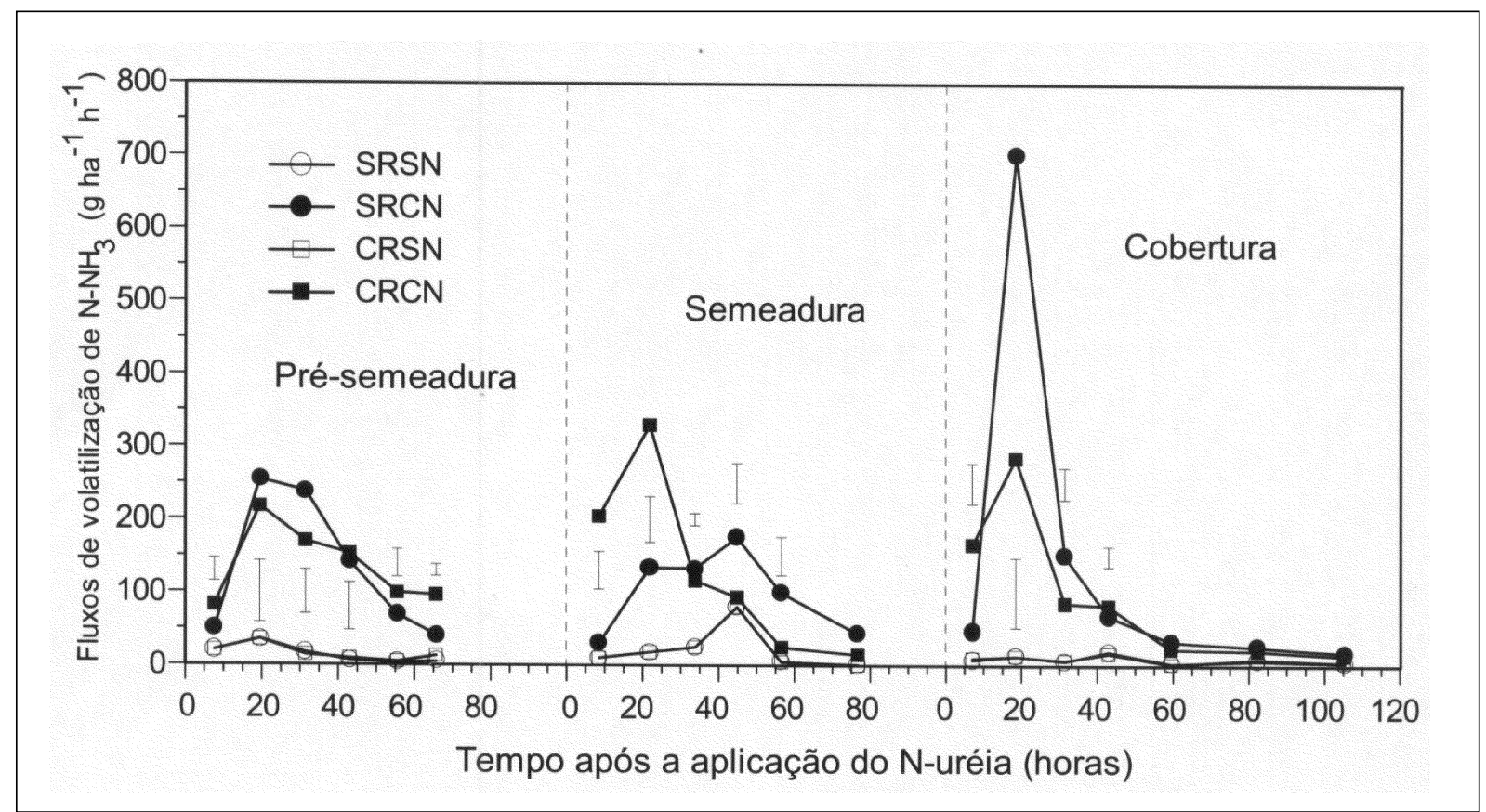

Figura 3 - Fluxos de volatilização de $\mathrm{N}^{-\mathrm{NH}_{3}}$ sem aplicação de uréia (SN) e com aplicação de $50 \mathrm{~kg} \mathrm{ha}^{-1} \mathrm{~N}$-uréia (CN) na pré-semeadura, semeadura e em cobertura, na presença (CR) e na ausência (SR) de resíduos culturais. As barras verticais indicam a diferença mínima significativa para cada época (Tukey 5\%).

Ciência Rural, v.35, n.4, jul-ago, 2005. 


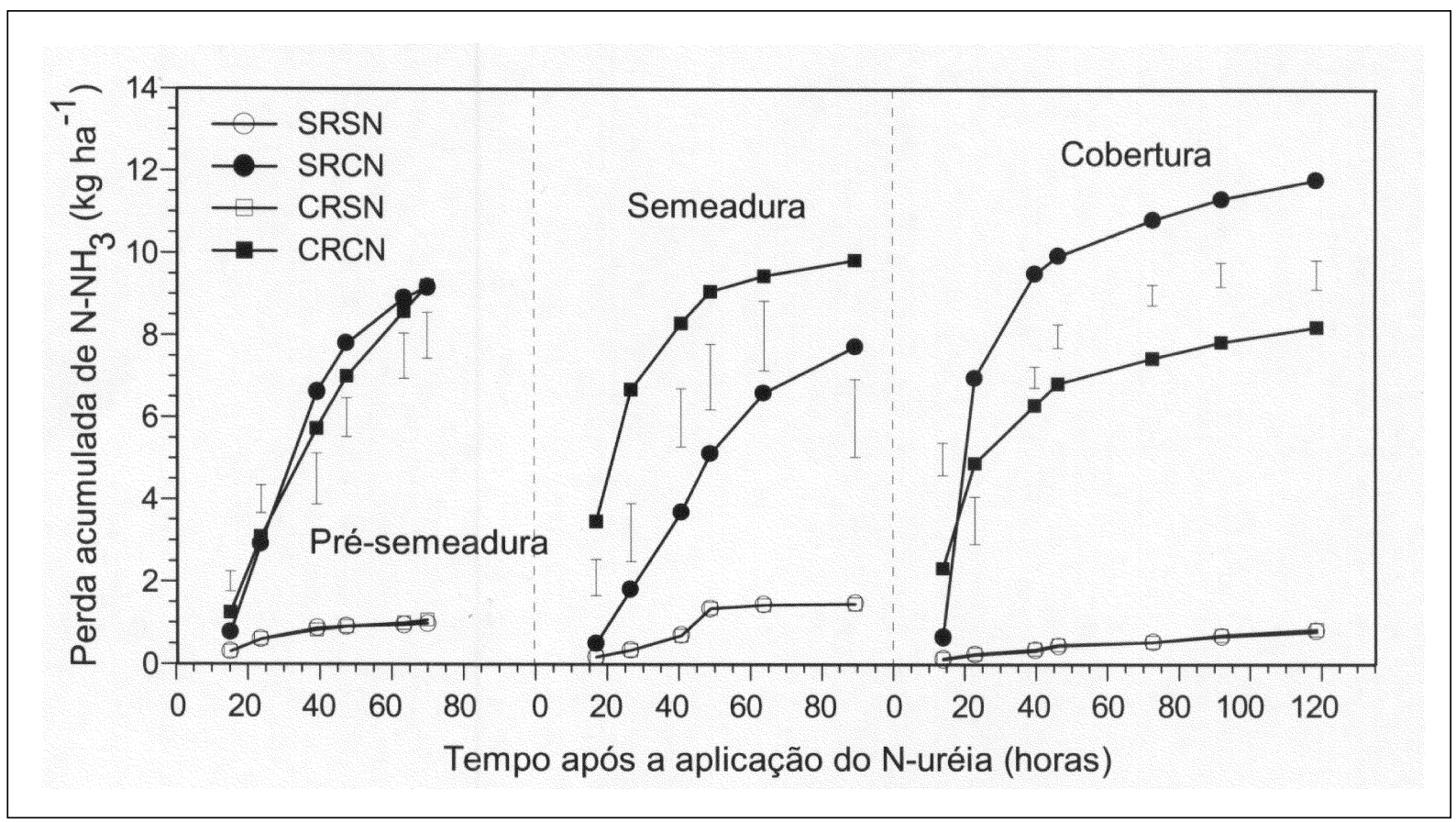

Figura 4 - Perda acumulada de $\mathrm{N}_{-} \mathrm{NH}_{3}$ sem aplicação de uréia ( $\left.\mathrm{SN}\right)$ e com aplicação de $50 \mathrm{~kg}$ ha ${ }^{-1} \mathrm{~N}$-uréia $(\mathrm{CN})$ na pré-semeadura, semeadura e em cobertura, na presença (CR) e na ausência (SR) de resíduos culturais. As barras verticais indicam a diferença mínima significativa para cada época (Tukey $5 \%$ ).

contribuíram para o aumento dos fluxos de volatilização de amônia nessa condição.

$\mathrm{Na}$ aplicação da uréia em cobertura, a precipitação pluviométrica ocorreu somente no final do segundo dia após a adubação nitrogenada (Figura 2) e teve pouca influência na incorporação da uréia ao solo, pois a maior parte da amônia já tinha sido volatilizada antes da ocorrência da precipitação (Figuras 3 e 4). Observa-se que, na primeira avaliação, posterior à aplicação da uréia, houve maior quantidade de amônia volatilizada na presença de resíduos

Tabela 1 - Umidade gravimétrica do solo na camada de zero a 10 $\mathrm{cm}$, imediatamente antes da aplicação da uréia na présemeadura do milho, na semeadura e em cobertura, na presença e na ausência de resíduos culturais de aveia

\begin{tabular}{lccc}
\hline \multirow{2}{*}{ Tratamentos } & \multicolumn{3}{c}{ Épocas de aplicação da uréia } \\
\cline { 2 - 4 } & Pré-semeadura & Semeadura & Cobertura \\
\hline \multirow{2}{*}{ Sem resíduos } & $18,3 \mathrm{a}^{(1)}$ & $15,8 \mathrm{a}$ & $12,8 \mathrm{~b}$ \\
Com resíduos & $19,3 \mathrm{a}$ & $17,5 \mathrm{a}$ & $14,8 \mathrm{a}$ \\
\hline
\end{tabular}

${ }^{1}$ Médias não seguidas pela mesma letra, na coluna, diferem pelo teste de Tukey a $5 \%$ de probabilidade de erro. culturais (Figuras 3 e 4), o que deve estar relacionado ao efeito do contato da uréia com o solo e da atividade da urease (NELSON et al., 1980; SANGOI et al., 2003).

$\mathrm{Na}$ segunda avaliação, o maior fluxo de volatilização ocorreu na ausência de resíduos culturais (Figura 3) e contribuiu para a maior quantidade acumulada de amônia volatilizada (Figura 4). A maior volatilização de amônia, na ausência de resíduos culturais, com aplicação da uréia em cobertura, pode ser justificada pela menor umidade do solo, em relação ao tratamento com resíduos culturais (Tabela 1). A temperatura do solo também é maior na ausência de resíduos culturais (BRAGAGNOLO \& MIELNICZUK, 1990) e, por isso, o pico de volatilização ocorreu no período das $9 \mathrm{~h}$ as $18 \mathrm{~h}$ do dia seguinte da aplicação (Figura 3). A maior temperatura favorece a atividade da urease e, assim, a taxa de hidrólise da uréia (CHIN \& KROONTJE, 1963) e facilita a difusão ascendente de amônia que ocorre juntamente com a evaporação da água do solo (AL-KANANI et al., 1991).

Ressalta-se que o efeito dos resíduos culturais na diminuição da volatilização de amônia ocorreu somente quando este manteve maior umidade no solo em relação ao solo descoberto. Isso aconteceu quando a uréia foi aplicada após um período de cinco 
dias sem chuva. Nessa situação, portanto, não se pode utilizar os resíduos culturais como justificativa para aplicação de uréia na superfície do solo. A melhor alternativa para minimizar as perdas de $\mathrm{N}$ por volatilização de amônia é incorporação da uréia ao solo, independente da presença ou da ausência de resíduos culturais (LARA CABEZAS et al., 2000 e SANGOI et al., 2003).

A quantidade total de $\mathrm{N}$ volatilizado proveniente da uréia, calculada por meio da diferença entre os tratamentos com e sem uréia, não foi afetada pela presença dos resíduos culturais de aveia, com valores médios de $17 \%$ do $\mathrm{N}$ aplicado (Tabela 2). Essa quantidade é relativamente baixa, comparado aos valores normalmente encontrados em condições de campo, com aplicação de uréia na superfície e sem incorporação ao solo (LARA CABEZAS et al.,1997b; LARA CABEZAS et al., 2000).

\section{CONCLUSÕES}

A presença de resíduos culturais de aveia na superfície do solo diminui as perdas de $\mathrm{N}$ por volatilização de amônia quando eles proporcionam maior umidade no solo, em comparação ao solo descoberto. Em condições semelhantes de umidade do solo, o que ocorre com a aplicação da uréia logo após a chuva, a volatilização de amônia é maior na presença de resíduos culturais. Quando ocorre chuva imediatamente após a aplicação da uréia, a volatilização

Tabela 2 - Quantidade de $\mathrm{N}-\mathrm{NH}_{3}$ volatilizado proveniente da aplicação da uréia (NVPU) na pré-semeadura, semeadura e em cobertura no milho, na presença e na ausência de resíduos culturais de aveia na superfície do solo

\begin{tabular}{|c|c|c|}
\hline \multirow{2}{*}{$\begin{array}{l}\text { Épocas de aplicação da } \\
\text { uréia no milho }\end{array}$} & \multicolumn{2}{|c|}{$\mathrm{NVPU}^{(1)}$} \\
\hline & Sem resíduos & Com resíduos \\
\hline & \multicolumn{2}{|c|}{ - } \\
\hline Pré-semeadura & $8,2 \mathrm{a}^{(2)}$ & $8,1 \mathrm{a}$ \\
\hline Semeadura & $6,3 \mathrm{~b}$ & $8,7 \mathrm{a}$ \\
\hline Cobertura & $11,0 \mathrm{a}$ & $7,4 \mathrm{~b}$ \\
\hline F interação & \multicolumn{2}{|c|}{$6,2^{*}$} \\
\hline $\mathrm{CV}(\%)$ & \multicolumn{2}{|c|}{18,2} \\
\hline Total absoluto $\left(\mathrm{kg} \mathrm{ha}^{-1}\right)$ & $25,5 \mathrm{a}$ & $24,2 \mathrm{a}$ \\
\hline Total relativo (\%) & $17,0 \mathrm{a}$ & $16,1 \mathrm{a}$ \\
\hline
\end{tabular}

Teste $\mathrm{F}$ significativo a $5 \%$ de probabilidade de erro. ${ }^{1} \mathrm{NVPU}=\mathrm{N}-\mathrm{NH}_{3}$ volatilizado com uréia $-\mathrm{N}-\mathrm{NH}_{3}$ volatilizado sem uréia.

${ }^{2}$ Médias não seguidas pela mesma letra, na linha, diferem pelo teste de Tukey a $5 \%$ de probabilidade de erro. de amônia é igual na presença ou na ausência de resíduos culturais.

\section{REFERÊNCIAS}

AL-KANANI, T. et al. Soil water and ammonia volatilization relationships with surface-aplied nitrogen fertilizer solutions. Soil Science American Journal, Madison, v.55, p.17611766, 1991.

BRAGAGNOLO, N.; MIELNICZUK, J. Cobertura do solo por resíduos de oito sequiências de culturas e seu relacionamento com a temperatura e umidade do solo, germinação e crescimento inicial do milho. Revista Brasileira de Ciência do Solo, v.14, p. $91-98,1990$.

BRASIL. Ministério da Agricultura. Departamento Nacional de Pesquisa Agropecuária. Divisão de Pesquisas Pedológicas. Levantamento de Reconhecimento dos Solos do Estado do Rio Grande do Sul. Recife, 1973. 431p. (Boletim Técnico, 30).

CERETTA, C.A. Manejo da adubação nitrogenada na sucessão aveia-milho, no sistema plantio direto. In: FRIES, M.R.; DALMOLIN, R.S.D. Atualização em recomendação de adubação e calagem: ênfase em plantio direto. Santa Maria : Pallotti, 1997. Cap.5, p.112-124.

CHIN, W.; KROOTJE, W. Ureia hidrolysis and subsequent loss of ammonia. Soil Science Society American Proceedings, v.27, p.316-318, 1963.

COSTA, M.C.G. et al. Volatilização de $\mathrm{N}-\mathrm{NH}_{3}$ de fontes nitrogenadas em cana-de-açúcar colhida sem despalha a fogo. Revista Brasileira de Ciência do Solo, v.27, p.631-637, 2003.

ECKERT, D.J. et al. Response of no-tillage grown in corn and soybean residues to several nitrogen fertilizer sources. Agronomy Journal, v.78, p.231-235, 1986.

EMBRAPA. Centro Nacional de Pesquisa de Solos. Sistema Brasileiro de Classificação de Solos. Brasília, 1999. 412p.

FALLEIRO, R.M. et al. Influência dos sistemas de preparo nas propriedades químicas e físicas do solo. Revista Brasileira de Ciência do Solo, v.27, p.10971104, 2003.

LARA CABEZAS, W.A.R. et al. Volatilização de $\mathrm{N}-\mathrm{NH}_{3}$ na cultura de milho: I. Efeito da irrigação e substituição parcial da uréia por sulfato de amônio. Revista Brasileira de Ciência do Solo, v.21, p.481-487, 1997a.

LARA CABEZAS, W.A.R. et al. Volatilização de $\mathrm{NNH}_{3}$ na cultura de milho: II. Avaliação de fontes sólidas e fluídas em sistema de plantio direto e convencional. Revista Brasileira de Ciência do Solo, v.21, p.489-496, 1997 b.

LARA CABEZAS, W.A.R. et al. Balanço da adubação nitrogenada sólida e fluída de cobertura na cultura de milho, em sistema de plantio direto no triângulo mineiro. Revista Brasileira de Ciência do Solo, v.24, p.363-376, 2000.

McINNES, K.J. et al. Ammonia los fron applications of ureaammonium nitrate solution to straw residue. Soil Science American Journal, v.50, p.969-974, 1986. 
MELLO, F.A.F. Uréia fertilizante. Campinas : Fundação Cargil, 1987. 192p.

MOAL, J.F. et al. Ammonia volatilization following surfaceapplied pig and cattle slurry in France. Journal of Agricultural Science, v.25, p.245-252, 1995.

NELSON, K.E. et al. Thatch influence on mobility and transformation of nitrogen carries applied to turf. Agronomy Journal, v.72, p.487-492, 1980.

NÖMMIK, H. The effect of pellet size on the ammonia loss from urea applied to forest soil. Plant and Soil, v.39, p.309318, 1973.

RODRIGUES, M.B.; KIEHL, J.C. Volatilização de amônia após emprego de uréia em diferentes doses e modo de aplicação. Revista Brasileira de Ciência do Solo, v.10, p.37-43, 1986.

SANGOI, L. et al. Volatilização de $\mathrm{N}-\mathrm{NH}_{3}$ em decorrência da forma de aplicação de uréia, manejo de resíduos e tipo de solo, em laboratório. Ciência Rural, v.33, p.87-692, 2003 .

SENGIK, E.; KIEHL, J.C. Efeito de resíduos orgânicos e do fosfato monocálcico na volatilização de amônia em terra tratada com uréia. Revista Brasileira de Ciência do Solo, v.19, p.321-326, 1995a

SENGIK, E.; KIEHL, J.C. Controle da volatilização de amônia em terra tratada com uréia e turfa pelo emprego de sais inorgânicos. Revista Brasileira de Ciência do Solo, v.19, p.455-461, 1995b.

SOUZA, Z.M.; ALVES, M.C. Propriedades químicas de um latossolo vermelho distrófico de cerrado sob diferentes usos de manejos. Revista Brasileira de Ciência do Solo, v.27, p.133-139, 1995.

TEDESCO, M.J. et al. Análise de solo, plantas e outros materiais. Porto Alegre : UFRGS, Faculdade de Agronomia, 1995. 174p. (Boletin Técnico de Solos, 5). 